keratoconjunctivitis [review]. Surv Ophthalmol 1987; 32:199-208.

6. Hoosen AA, Mody GM, Goga IE, Kharsany AB, Van den Ende J. Prominence of penicillinase-producing strains of Neisseria gonorrhoeae in gonococcal arthritis: experience in Durban, South Africa. Br J Rheumatol 1994;33:840-1.

7. Ross JD, Moyes A, McMillan A, Young H. Temporal changes in the sensitivity of Neisseria gonorrhoeae to penicillin in Edinburgh. Int J STD AIDS 1995;6:110-3.

8. Lewis DA, Ison CA, Livermore DM, Chen HY, Hooi AY, Wisdom AR. One year survey of Neisseria gonorrhoeae isolated from patients attending a genitourinary medicine clinic: antibiotic susceptibility patterns and patients' characteristics. Genitourin Med 1995;71:13-7.

9. Tapsall JW, Phillips EA. The sensitivity of 173 Sydney isolates of Neisseria gonorrhoeae to cefpodoxime and other antibiotics used to treat gonorrhea. Pathology 1995;27:64-6.

10. Cummings MC, Covino JM, Smith BL, Ratiu ES, Draft $\mathrm{K}$, McCormack WM. Susceptibility of isolates of Neisseria gonorrhoeae to penicillin and tetracycline in Brooklyn 1988-1992. Sex Transm Dis 1995;22:110-3.

11. Reed K, Jones MW. PPNG conjunctivitis. J Am Opt Assoc 1984;55:425-7.

Sir,

\section{Paediatric Ophthalmology in West Mostar, Bosnia}

During 1992-1994 the war in Bosnia-Hercegovina crippled many towns and produced many refugees and displaced persons. Since May 1993, the East Bank of Mostar has been without adequate food, running water or medical supplies. Eighty per cent of the buildings have been destroyed and its population has existed mainly on international humanitarian aid. Many of the children in East Mostar have spent around 10 months living in basements.

As a result of the conflict, the Department of Paediatrics, Keele University, in conjunction with UNICEF, has supported a team of paediatricians who have provided medical care for the children in Mostar. Children found to have ophthalmic problems were registered for subsequent re-evaluation. This report contains the results of an ophthalmologist's assessment of the children living on the East Bank of Mostar.

\section{Materials and Methods}

Between May and September 1994, Keele University paediatricians established a screening programme that aimed to examine all children in the Mostar region. A total of 5823 children, 16 years or under, were assessed in Mostar of which 3851 lived on the East Bank, $49 \%$ of which were female. Comprehensive civilian records suggest that about $90 \%$ of all children were examined. The age of the population is given in Fig. 1. There are slightly fewer children than expected under the age of 5 years due to the reduced birth rate, increased infant mortality and relocation of some mothers with very young children.

This programme utilised three mobile health centres that carried comprehensive examination and treatment equipment including an ophthalmoscope. The paediatric assessment was conducted by paediatricians of consultant or registrar status and included a full history and a complete systemic and ophthalmic examination. All general and ophthalmic information was prospectively and uniformly recorded using standardised sheets and logged onto a computerised database by the examining paediatrician, typically that evening. Children who were prospectively identified for subsequent ophthalmic assessment had: any history of ophthalmic disease, an active ophthalmic problem, or the probability of a problem that required confirmation. Of the 3851 children screened from the East Bank of Mostar, 135

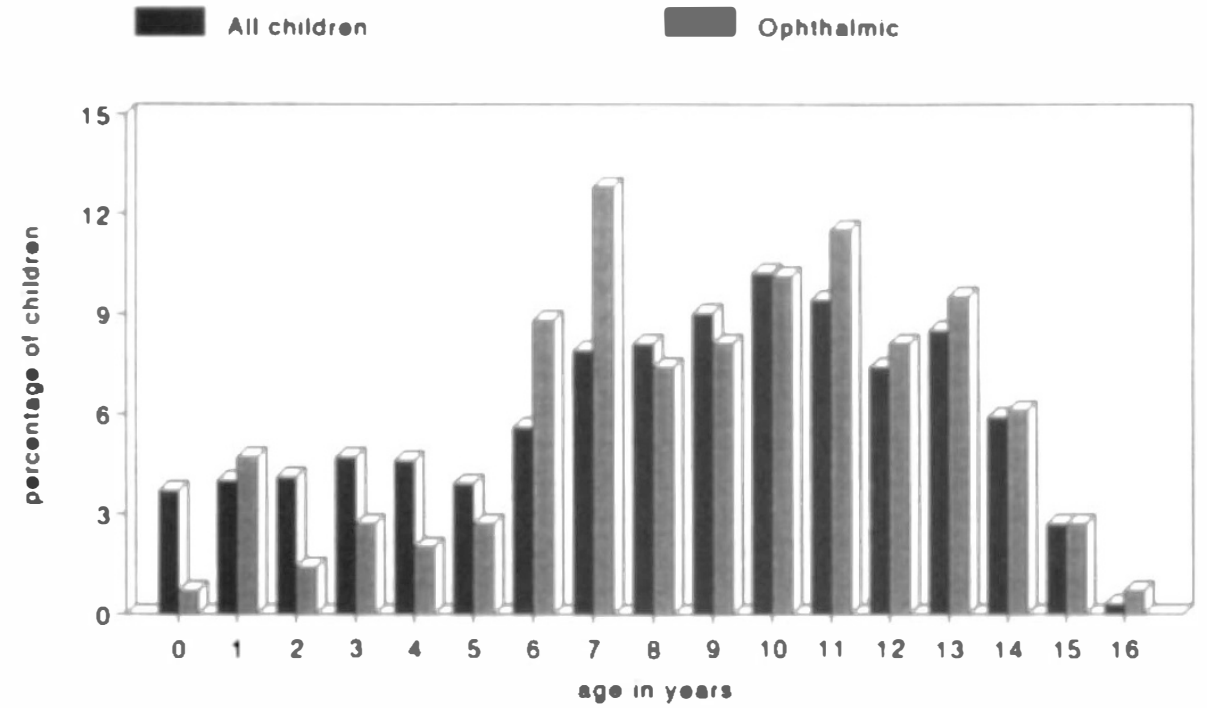

Fig. 1. The age distribution of all children attending screening in East Mostar $(\mathrm{n}=3851)$ as compared with the 135 children identified as having ophthalmic problems. 
(3.5\%) were considered to have such an ophthalmic problem by the paediatricians.

Because of the lack of local examination equipment, a complete range of ophthalmic instruments was brought from the UK. This included a slit lamp microscope, direct and indirect ophthalmoscopes, a retinoscope, applanation tonometry, Titmus stereo tests, prism bars and colour vision tests. Visual acuity assessment used the Sonksen-Silver Acuity System with and without letter matching. Preverbal children were assessed with the Cardiff preferential looking charts. ${ }^{1.2}$

The children were called to the clinic using the local radio service. Typically, $60 \%$ of children would attend with only one announcement. A full ophthalmic examination included visual acuity, anterior segment examination, funduscopy, retinoscopy and refraction. Amblyopia was defined as a difference in visual acuity of two Snellen lines or greater, when best corrected and in the absence of ophthalmic pathology. Significant refractive errors were defined as myopia $>0.75 \mathrm{sph}$, hypermetropia $>+1.5 \mathrm{sph}$, astigmatism $>1.5$ dioptres and anisometropia $>1.0$ dioptre. Strabismus was diagnosed on the basis of clinical examination. The data were recorded prospectively using standardised data sheets.

\section{Results}

Fig. 1 shows the age distribution of all children in East Mostar as compared with the 135 children identified as having ophthalmic problems. Of these $135,60(44 \%)$ were female and all were 16 years or younger. A total of 103 children were able to be recalled and examined $(76 \%)$. All children had a best corrected visual acuity of $6 / 18$ or better in the better seeing eye. The diagnoses are detailed in Table I. Of the eyes with esotropia, 14 of $27(52 \%)$ were amblyopic, 8 of 27 (30\%) were hypermetropic and 6 of $27(22 \%)$ were anisometropic. Of the children with esotropia over the age of 7 years, $48 \%$ were amblyopic. No child with amblyopia had a visual acuity of worse than 6/36 in that eye. A total of 44 of 103 children originally had spectacles, and of these 17 $(38 \%)$ had lost, broken or had their spectacles stolen as a result of the war. There have been no facilities to make, supply or repair spectacles in East Mostar for the last 18 months. Eighteen eyes were normal to examination (18\%). Of these, 8 were thought to have a squint by the paediatricians but not by the ophthalmologist. The only other 'incorrect' diagnosis was a chalazion that was mistaken for a dermoid.

The eyes with penetrating intraocular injuries had ultimate visual acuities of $6 / 18,6 / 36,6 / 36,6 / 60$, hand movements, hand movements and perception of light. All injuries were from bomb blasts or shrapnel. Only one injury was bilateral although 4 children had lost other organs or limbs at the same time. During the 1 year of shelling from August 1993 to September 1994, 6 of 3851 children received penetrating ocular injuries which equates to $160 / 100000$ per year.

\section{Discussion}

In this study, screening of children for visual problems by paediatricians led to an ophthalmic referral in $3.5 \%$ of cases. Of these, ophthalmic problems were confirmed by an ophthalmologist in $2.9 \%$ of the population screened. This compares with the American National Society to Prevent Blindness (ASPB) survey of 3- to 6-year-olds of whom 4.4\% were referred and $2.6 \%$ had actual ophthalmic diagnosis including refractive errors. ${ }^{3}$ The prevalence of refractive errors increases during childhood. In the UK, $10-12 \%$ of 10 -year-olds have been prescribed spectacles, although overprescribing had probably occurred in up to $40 \%$ of these. ${ }^{4}$ This study examined children aged $0-16$ years and, therefore, it is probable that a significant number of refractive errors are not being detected in screening.

The main ocular problems in the children of East Mostar were strabismus (33\%), refractive errors $(45 \%)$ and amblyopia (21\%). These findings are similar to the ASPB data on 214492 children aged 3-6 years: strabismus $13 \%$, refractive errors $69 \%$ and amblyopia $18 \%{ }^{3}$ The paediatricians' ability to assess and refer these children appropriately for ophthalmic assessment was good. The only problem highlighted was that of the diagnosis of squint.

Amblyopia was very common in the children with esotropia (52\%) and this compares with rates in other studies of $35-42 \%{ }^{5,6}$ Of the subgroup over the age of 7 years, and hence no longer treatable, $48 \%$ had residual amblyopia. Most had previously received some management for the amblyopia. This included correction of refractive errors and pleoptics. This compares with rates of residual amblyopia in other series of $44 \%,{ }^{7} 36 \%,{ }^{8} 31 \%,{ }^{9}$ and $3 \%{ }^{10}$ Therefore, the prevalence of amblyopia may be higher than reported elsewhere. ${ }^{11}$ For many children, this will reflect the local ophthalmic management before the war.

The incidence of penetrating ocular injuries was $160 / 100000$. This is $40 \times$ that of the West Bank and Gaza strip, ${ }^{12} 66 \times$ that of Northern Ireland ${ }^{13,14}$ and $800 \times$ that of Wisconsin, USA. ${ }^{15}$ It is probable that the incidence is under-represented in East Mostar because some of the injuries would have been incompatible with life and hence not included in this series.

Penetrating ocular injuries make up $9-48 \%$ of all ocular trauma to children ${ }^{16.17}$ and childhood trauma per se makes up $27-52 \%$ of all ocular trauma. ${ }^{13,14}$ Therefore, a similar incidence would be expected in the adults. 
Table I. Diagnosis of ophthalmic problems

\begin{tabular}{ll}
\hline Diagnosis & Number $(n=103)$ \\
\hline Squint & $34(33 \%)$ \\
Esotropia & 27 \\
Exotropia & 5 \\
Duane's & 2 \\
Amblyopia & $22(21 \%)$ \\
Simple refractive errors ${ }^{\mathrm{a}}$ & $31(30 \%)$ \\
Myopia & 13 \\
Hypermetropia & 12 \\
Astigmatism & 6 \\
Penetrating ocular trauma & 6 \\
Allergic eye disease & 2 \\
Blepharoconjunctivitis & 2 \\
Conjunctival naevus & 2 \\
Chalazion & 2 \\
Congenital cataracts & 1 \\
Blocked lacrimal duct & 1 \\
Eyebrow haemangioma & 1 \\
Heterochromia & 1 \\
Iris and chorioretinal coloboma & 1 \\
Ptosis & 1 \\
Congenital nystagmus & 1 \\
Normal eyes & $18(17 \%)$ \\
\hline
\end{tabular}

${ }^{a}$ Not associated with strabismus.

In this war-time European example, the patient recall of this preselected group was $76 \%$. This is good considering that the time from paediatric assessment to ophthalmic assessment was up to 6 months and some of the refugee families may have moved away from the Mostar area. Further, this study has shown that expert paediatric screening generates ophthalmic referral in $3.5 \%$ of cases. The unknown variable is what ophthalmic pathology is contained in the other $96.5 \%$ of non-referred patients. This is particularly important for the pre-verbal children. Future work will consider this area and use options such as photoscreening to assess strabismus and refractive errors. ${ }^{18-23}$ These techniques offer sensitivities and specificities of 0.94 and 0.94 respectively. ${ }^{21}$ The greatest yield and best therapeutic outcome from screening for strabismus and refractive errors occurs if the screening is at approximately 18 months. ${ }^{11,23}$

The authors are grateful to Janet Silver, Prof. Gordon Johnson, Claire Gilbert and the UNICEF/Keele University team in Mostar for their help in this project. This project was funded by the Overseas Development Administration.

Mark Elder, MD, FRACS, FRACO

Moorfields Eye Hospital and Institute of Ophthalmology

London

UK

David Southall, MD, FRCP

Department of Academic Paediatrics

University of Keele

North Staffordshire Hospital

Stoke-on-Trent

UK and

UNICEF

Zagreb

Former Yugoslavia

Correspondence to:

Mark J. Elder

Ophthalmology Department

Christchurch Hospital

Private Bag 4710

Christchurch

New Zealand

Fax: +64 (3) 3640273.

\section{References}

1. Adoh TO, Woodhouse JM, Oduwaiye KA. The Cardiff Test: a new visual acuity test for toddlers and children with intellectual impairment. A preliminary report. Optom Vis Sci 1992;69:427-32.

2. Adoh TO, Woodhouse JM. The Cardiff acuity test used for measuring visual acuity development in toddlers. Clin Vis Sci (in press).

3. Ehrlich MI, Reinecke RD, Simons K. Preschool vision screening for amblyopia and strabismus: methods, guidelines, 1983. Survey Ophthalmol 1983;28:145-63.

4. Stewart-Brown S. Spectacle prescribing among 10year-old children. Br J Ophthalmol 1985;69:874-80.

5. Noorden GK von. A reassessment of infantile amblyopia. Am J Ophthalmol 1988;105:1-10.

6. Costenbader F, Blair D, McPhail A. Vision in strabismus. Arch Ophthalmol 1948;40;438-53.

7. Fells P. Richardson Cross Lecture 1989. Amblyopia: an historical perspective. Eye 1990;4:775-86.

8. Oliver M, Nawratzki I. Screening of pre-school children for ocular anomalies. II. Amblyopia. Prevalence and therapeutic results at different ages. $\mathrm{Br} \mathrm{J}$ Ophthalmol 1971;55:467-71.

9. Scobee RG. Esotropia: incidence, aetiology and results of therapy. Am J Ophthalmol 1951;34:817-33.

10. Lithander J, Sjostrand J. Anisometropic and strabismic amblyopia in the age group 2 years and above: a prospective study of the results of treatment. Br J Ophthalmol 1991;75:111-6.

11. Neumann E, Friedman Z, Abel-Peleg B. Prevention of strabismic amblyopia of early onset with special reference to the optimal age of screening. J Pediatr Ophthalmol Strabismus 1987;24:106-10.

12. Elder MJ. Penetrating eye injuries in children of the West Bank and Gaza strip. Eye 1993;7:429-32.

13. Johnston S. Perforating eye injuries: a five-year survey. Trans Ophthalmol Soc UK 1971;91:895-921.

14. Canavan YM, O'Flaherty MJ, Archer DB, Elwood JH. A 10-year survey of eye injuries in Northern Ireland, 1967-1976. Br J Ophthalmol 1980;64:618-25.

15. Karlson TA, Klein BEK. The incidence of acute hospital-treated eye injuries. Arch Ophthalmol 1986; 104:1473-6.

16. Niiranen M, Raivio I. Eye injuries in children. Br J Ophthalmol 1981;65:436-8.

17. Moriera CA, Debert-Ribeiro M, Belfort R. Epidemiological study of eye injuries in Brazilian children. Arch Ophthalmol 1988;106:781-4.

18. Molteno AC, Hoare-Nairne J, Parr JC, Simpson A, Hodgkinson IJ, O'Brien NE, Watts SD. The Otago photoscreener, a method for the mass screening of 
infants to detect squint and refractive errors. Trans Ophthalmol Soc NZ 1983;35:43-9.

19. Molteno AC, Sanderson GF, Hoare-Nairne J. Clinical experience with the Otago photoscreener. Aust NZ J Ophthalmol 1985;13:49-58.

20. Molteno AC, Hoare-Nairne J, Sanderson GF, Peart DA, Hodgkinson IJ. Reliability of the Otago photoscreener: a study of a thousand cases. Aust NZ J Ophthalmol 1994;21:257-65.

21. Kennedy RA, Sheps SB. A comparison of photoscreening techniques for amblyogenic factors in children. Can J Ophthalmol 1989;24:259-64.

22. Freedman HL, Preston KL. Polaroid photoscreening for amblyogenic factors: an improved methodology. Ophthalmology 1992;99:1785-95.

23. Hope C, Roulston J, Hoey C, Wong A, Clover G. Community photoscreening of six to nine month old infants for amblyogenic factors. Aust NZ J Ophthalmol 1994;22:193-202.

Sir,

\section{Psychogenic Erectile Dysfunction Complicating Ophthalmic Surgery}

Male sexual impotence associated with ocular disease or therapy is not frequently encountered in ophthalmic practice. Erectile dysfunction (ED) is now the preferred term for this condition and is defined as the inability of the male to achieve an erect penis as part of the overall multifaceted process of male sexual function'. We report a case of psychogenic erectile dysfunction resulting from cataract extraction. To our knowledge this is the first report of ED complicating ophthalmic surgery. The causes of diminished erectile ability in patients with ocular disease are discussed.

\section{Case Report}

A 53-year-old man was referred to the ophthalmic outpatient department in 1987 because of a 2 year history of gradual and painless deterioration of vision in both eyes. He was systemically fit and well and was receiving no medications. Examination revealed a visual acuity of $6 / 18$ in the right eye and 6/24 in the left eye and significant bilateral lens opacities. No other ocular pathology was noted.

Left extracapsular cataract extraction (ECCE) with posterior chamber intraocular lens (PCIOL) implantation was performed in 1988. This was complicated in the post-operative period by displacement of the PCIOL. The intraocular lens was removed in 1992 and replaced with an anterior chamber IOL. Unfortunately post-operative astigmatism $\left(+8.0\right.$ dioptres at $\left.12^{\circ}\right)$ necessitated refractive surgery in the form of compression sutures. Following left YAG posterior capsulotomy a best corrected final visual acuity of $6 / 5$ was achieved in this eye.

Right ECCE and PCIOL implantation was successfully undertaken in 1990 resulting in a best corrected final visual acuity of 6/5. The patient was delighted with the visual result in both eyes.
The patient came for final follow-up to the outpatient department in 1995 . He had no visual complaints but did report post-coital retro-orbital pain bilaterally and said he was afraid to partake in sexual relations with his partner in case his eyes would 'burst open'. Visual acuity was $6 / 5$ bilaterally. Anterior segment findings were consistent with previous surgical procedures, there was no evidence of narrow angles on gonioscopy and the intraocular pressures were normal. No fundus abnormalities were noted.

Psychosexual assessment revealed that the patient had been suffering from diminished erectile ability for the previous 3 years and loss of orgasmic pleasure on ejaculation. Sexual intercourse with his wife is only possible when he is sure that she is comfortable as she suffers from severe cervical spondylitis. $\mathrm{He}$ still achieved very good early morning erections and nocturnal emissions. Interestingly, as a teenager he had been told at school that too much sex would make him blind and he assumed that this was the cause of his cataracts. The following investigations were normal: serum prolactin, serum cholesterol, serum triglycerides, serum HDL cholesterol, blood glucose and thyroid function tests. Testosterone was slightly low at $10 \mathrm{nmol} / \mathrm{l}$.

\section{Comment}

ED has traditionally been classified as either psychogenic or organic. However, it is now recognised that in many cases both psychological and medical factors play a role and are interactively additive. ${ }^{1}$ It is therefore important to identify all aetiopathogenic factors in cases of ED if the condition is to be treated appropriately.

The most reliable discriminators between primarily functional and primarily biogenic ED include nocturnal penile tumescence and the presence and rigidity of morning erections. ${ }^{2}$ Sleep erections reflect the potential of the penis to become rigid unencumbered by psychological factors. The patient reported here experienced both nocturnal emissions and morning erections.

Acute attacks of angle closure glaucoma provoked by sexual intercourse have been described. ${ }^{3}$ However, the patient described here had deep anterior chambers and wide-open angles.

We believe the retro-orbital pain reported by our patient was psychosomatic in origin, reflecting his concern over his wife's comfort during intercourse. These symptoms in turn resulted in anxiety regarding the health of his eyes following the multiple ophthalmic procedures he had undergone, and the fear that his eyes might 'burst open' during lovemaking. This sequence of events resulted in ED.

This case represents the first report of psychogenic ED complicating ophthalmic surgery. The organic 